\title{
Helmut Auweter
}

Published online: 2 December 2003 (c) Springer-Verlag 2003

\section{Proceedings}

The series of meetings of the Kolloid-Gesellschaft for young scientists ("Nachwuchstage") was continued this year with its seventh coming together on 3 and 4 April 2003. The meeting took place at the Ruprecht-Karls-Universität in Heidelberg and was hosted by Professor Michael Grunze. Young scientists, graduate students and postdoctoral researchers presented 18 oral contributions and 30 posters to an audience of about 75 participants.

The topics were spread very broadly and covered the range from conductive nanoparticulate systems, nanocontainers for drug delivery and photonic crystals to associative polymers, polymer dispersions, membranes, interfaces and biological systems. Advances in measurement techniques like TIRM (total internal reflection microscopy), streaming current potential and MIES (metastable induced electron spectroscopy) were shown to bring further insight into the interactions and structure of colloidal systems.

Two poster presentations were awarded with the Springer Poster Award:

- Feng Yan and Werner A. Goedel, University of Ulm: "Tuning the pore size of porous membranes derived from 2D monolayer of silica particles".

- Karina Radomsky and H. Rehage, University of DuisburgEssen: "Visualisation of flow-induced phenomena at liquid-liquid phase boundaries".

In the late afternoon of April 3rd, the nearby Ludwigshafen site of BASF was visited and the participants were given insights into colloid research at BASF as well as information on a successful career in industry as a young researcher.

Information on the KolloidGesellschaft meetings and conferences can be found at http://www. kolloidgesellschaft.de. 